\title{
DOES BANNING PRICE DISCRIMINATION PROMOTE ENTRY AND INCREASE WELFARE? A MODEL OF DIFFERENTIATED-PRODUCT DUOPOLY WITH ASYMMETRIC MARKETS*
}

\author{
by \\ SÍLVIA FERREIRA JORGE \\ GOVCOPP and DEGEI, Universidade de Aveiro, Portugal \\ and \\ CESALTINA PACHECO PIRESं \\ CEFAGE-UE and Universidade de Évora, Portugal
}

\begin{abstract}
In this paper we investigate the impact of firms' pricing policies upon entry and welfare under duopoly price competition and product differentiation. We consider a model where an incumbent serves two distinct and independent geographical markets and an entrant may enter in one of the markets. Our results show that discriminatory pricing may be either more, less or equally favorable to entry than uniform pricing. The welfare effect of banning price discrimination is also ambiguous. However, the case for banning price discrimination is much weaker than under monopoly. Interestingly, discriminatory pricing may yield higher welfare even when entry occurs only under uniform pricing.
\end{abstract}

\section{INTRODUCTION}

There are many circumstances where firms are not allowed to price discriminate. For instance, cross-market price restrictions are often part of universal service requirements (such as postal delivery, railroad transport, telecommunications and gas markets). ${ }^{1}$ Similarly, in anti-dumping legislation firms are not allowed to price discriminate across countries (see Prusa, 1994). There are also examples of firms using non-discriminatory prices, such as in pharmaceutical markets where global reference pricing is common (see Lanjouw, 1997) and in most-favored-costumer rules (for Medicaid, liquor and leadbased antiknock compounds markets in USA, see, respectively, Scott Morton, 1997; Degraba, 1987; Hay, 1994).

Therefore an important economic policy issue is whether price discrimination should be prohibited or not. To answer this question one should not limit the analysis to a comparison between uniform pricing and discrimina-

* Manuscript received 18.3.11; final version received 16.10.11.

$\dagger$ We gratefully acknowledge financial support from Fundação para Ciência e Tecnologia (FCT) (BD/857/2000) and Fundo Social Europeu, III EU Framework; financial support to the FCT project PTDC/GES/70529/2006 and partial financial support from FCT, program FEDER/POCTI.

${ }^{1}$ In the late 20th century, there was regulation on the British telecommunications market in terms of the local and long-distance call charges and the Monopolies and Mergers Commission (1988) removed the freedom to discriminate in the British gas market. 